\title{
PENINGKATKAN PENGUASAAN KOSAKATA BAHASA INGGRIS MELALUI METODE VCD PADA SISWA KELAS II DI SD N ROROTAN 03 PAGI KELURAHAN ROROTAN CILINCING JAKARTA UTARA
}

\author{
Ika Yulistiana*
}

\begin{abstract}
Abstrak
The purpose of this study was to improve the mastery of English vocabulary through the VCD media method on class II students in SD N Rorotan 03 Morning Village in Rorotan Sub-District, Cilincing District, North Jakarta. This research was conducted on 32 year old children. This study was an action research with Kemmis and Taggart models consisting of 4 stages namely (plan, action, observation and reflection). This study consisted of 2 cycles, with each cycle as many as four meetings. Data collection techniques are using observation, field notes, and documentation. Data analysis uses quantitative and qualitative. Quantitative data analysis is carried out with statistical descriptions to compare pre cycles to the second cycle. The stages of qualitative analysis are data reduction, display data and verification. The results showed that there was an increase in English vocabulary mastery through the VCD media method. The results of the study quantitatively addressed the learning outcomes of vocabulary improvement in 32 children with an average of $58.53 \%$ so that the results had not reached KKM, then continued in the first cycle to experience the average vocabulary ability is $7 \mathrm{I} .31 \%$ and then in cycle II the average vocabulary is 84 . $06 \%$.
\end{abstract}

Keywords: Mastery of vocabulary English words and VCD methods

\section{PENDAHULUAN}

Bahasa Inggris juga merupakan bahasa kedua atau bahasa resmi dibanyak negara didunia termasuk sebagian negara - negara Asia. Bahasa Inggris dianggap sebagai bahasa Internasional penting dipelajari untuk di era 4. 0 . Kecenderungan masyarakat akan bahasa asing tersebut, membuat berbagai lembaga pendidikan saling berlomba membuat program yang memasukan Bahasa Inggris sebagai salah satu keahlian yang dikembangkan. Anak yang menguasai bahasa asing memiliki kelebihan dalam hal inelektual yang fleksibel, keterampilan

* STAI AL Aqidah Al Hasyimiyyah Jakarta Email: annab3llia@yahoo.co.id 
akademik, berbahasa dan sosial. Selain itu, anak akan memiliki kesiapan memasuki suatu konteks pergaulan dengan berbagai bahasa dan budaya. Sehingga ketika dewasa anak akan menjadi sumber daya manusia yang berkualitas dan bisa berprestasi. Berdasarkan teori tersebut adalah tepat jika bahasa Inggris mulai diperkenalkan kepada anak sedini mungkin. Hal ini berdasarkan asumsi bahwa masa sensitif bahasa dalam kehidupan seorang anak adalah antara nol sampai delapan tahun. Segala macam aspek dalam berbahasa harusdapat diperkenalkan kepada anak sebelum masa sensitif ini berakhir. Pada priode sensitif ini sangat penting diperkenalkan cara berbahasa yang baik dan benar, karena keahlian ini sangat berguna untuk berkomunikasi dengan lingkungannya ${ }^{1}$.

Pengenalan bahasa Inggris dengan cara yang tepat dapat memudahkan anak memahami bahasa Inggris pada tahapan selanjutnya. Demikian pula sebaliknya, pengenalan bahasa Inggris yang keliru bagi anak usia dini, dapat mengakibatkan kemungkinan terjadinya kesulitan penguasaan bahasa pada tahapan perkembangan berikutnya. Stimulasi-stimulasi yang tepat dapat membantu merangsang program yang mapan dan berkesinambungan untuk menciptakan suatu program yang memang efektif untuk diterapkan dilembaga pendidikan, sebagai uaya untuk mengefektifkan program maka juga perlu didukung oleh sistem manajemen, sehingga poses pembeajaran dapat berjalan sebaik mungkin. ${ }^{2}$ Pembelajaran bahasa Inggris dimulai dari belajar kosakata yang sering digunakan dalam sehari-hari, misalnya yang berhubungan dengan anggota tubuh, hewan, dan lainnya. Hal ini karena siswa akan lebih mudah belajar tentang hal konkret yang sering siswa temui. Pembelajaran bahasa Inggris bagi siswa kelas dua awal yang masih belum lancar menulis, akan lebih ditekankan pada pengenalan dan penguasaan kosakata secara lisan. Keterbatasan menggunakan kosakata bahasa Inggris dirumah membuat penerimaan dan ekpresi anak - anak akan vocabulary juga menjadi terbatas. Keterbatasan vocabulary anak, tidak hanya disebabkan karena kurangnya pembiasaan menggunakan

1 Martini Jamaris, Perkembangandan Pengembangan AnakUsia Taman Kanak-kanak. (Jakarta: Gramedia, 2006), h. 141

2 Ahmad Fauzi, Organizational Culture of Islamic Public Education Management a Discurtive, in International Conference On Islamic Education (ICIED) Innovations, Approaches, Challenges, And The Future, (Malang: Fakultas Ilmu Tarbiyah dan Keguruan UIN Maulana Malik Ibrahim Malang, 2017), 130-36. 
bahasa Inggris dirumah, tetapi juga tidak digunakannya bahasa Inggris sebagai bahasa pengantar dalam pembelajaran bahasa Inggris disekolah. Dengan pembiasaan menggunakan bahasa Inggris ketika dirumah ataupun disekolah, menjadikan anak lebih mudah mempelajari bahasa Inggris. Dengan mengenalkan cara berbahasa yang baik dan benar berguna bagi anak untuk membangun berkomunikasi dengan lingkungannya. Untuk bisa menguasai bahasa Inggris salah satunya dengan carapenguasaan kosakata sebagai dasar pembelajaran bahasa Inggris. Di setiap keterampilan berbahasa seperti menyimak, berbicara, membaca, dan menulis penguasaan kosakata amat diperlukan. Tanpa penguasaan kosakata yang memadai akan sulit bagi anak untuk menguasai bahasa asing, karena pada dasarnya bila kita mempelajari bahasa asing sesungguhnya kita mempelajari kosakata bahasa itu sendiri.

Dalam pembelajaran, kosakata tidak hanya mengetahui cara pengucapannya dan ejaannya, tetapi anak juga memahami makna dari kosakata yang dipelajari. Dengan memahami kosakata yang diketahuinya, anak dapat menyampaikan suatu pesan dengan baik. Pemahaman dalam mempelajari kosakata dalam bahasa Inggris adalah salah satu cara efektif dalam belajar bahasa inggris pada anak usia dini. Keberhasilan anak dalam menguasai kemampuan bahasa inggris, tidak terlepas dari peran guru atau orang dewasa dalam memberikan penanaman konsep awal bahasa Inggris. Dengan demikian, kemampuan pendidik dalam menciptakan lingkungan belajar mengajar menjadi unsur terpenting demi terciptanya peningkatan kemampuan bahasa Inggris dalam diri anak. Kegiatan belajar mengajar yang disajikan dengan pendekatan yang tepat diharapkan dapat membangkitkan minat anak untuk belajar bahasa Inggris dan memudahkan anak untuk memahami konsep yang diajarkan oleh guru, Namun kenyataan dilapangan menunjukan bahwa masih banyak pendidikan formal disekolah yang tidak menstimulasi anak didiknya untuk mengembangkan kemampuan berbahasa Inggris. Alasan lain adalah pada umumnya bahasa Inggris disekolah tidak disajikan dengan cara yang menarik oleh guru dapat menguggah minat belajar anak dalam meningkatkan penguasaan kosa kata. 


\section{PEMBAHASAN}

\section{Hakikat Bahasa Pada Anak}

Bahasa merupakan suatu kebutuhan bagi setiap anak. Dengan bahasa anak dapat berkomunikasi dengan orang lain, mengutarakan pendapatnya, mengeluarkan emosinya, dan dapat menunjang perkembangan kognitifnya. Beberapa fungsi bahasa menurut Ahmad Izzan antara lain: (1) Bahasa digunakan manusia untuk memenuhi kebutuhan dasarnya dan mencapai maksudnya serta beberapa kepentingannya dalam rangka aktualisasi diri, (2) Bahasa dapat digunakan untuk mengungkapkan emosi, harapan, keinginan, citacita dan pikiran seseorang. Bahasa juga dapat membuat orang lain mengerti perasaan diri kita, (3) Bahasa adalah alat berfikir ketika sebuah ide atau gagasan muncul, ia belum berbentuk. Namun setelah dituangkan dalam bentuk kata-kata yang diucapkan lisan atau ditulis dengan simbol-simbol maka ide itu berubah menjadi bahasa karena sudah berwujud, (4) Bahasa dapat digunakan untuk mempengaruhi orang lain baik digunakan secara lisan maupun tulisan, (5) Bahasa merupaka media penghubung antara satu orang dengan orang lain melalui komunikasi, (6) Bahasa dapat menjadi alat pemersatu bangsa, dimana potret masyarakat Indonesia begitu beragam ${ }^{3}$.

Pemerolehan bahasa setiap anak berbeda beda, hal ini dapat dipengaruhi oleh stimulasi yang diberikan kepada anak. Stimulasi yang diterima oleh anak kemudian mempengaruhi pemerolehan bahasa kedua. Menurut penelitian Ahmad Izzan belajar bahasa kedua termasuk sukar, baik bahasa yang digunakan secara umum oleh masyarakat luas (bukan bahasa dalam keluarga) maupun yang digunakan oleh orang asing (di luar masyarakat dalam kelompok atau bangsa). ${ }^{4}$ Oleh sebab itu, dalam belajar bahasa kedua inilah diperlukan metode belajar dan pengajar yang seutuhnya. Mengajar bahasa memiliki empat faktor yaitu pengajar, metode, pengajaran bahasa, dan materi belajar. Guru di sini dapat juga disebut dengan fasilitator yang sebaiknya mencari metode dan memakai alat-alat media yang efektif dalam membantu pembelajaran bahasa.

3 Ahmad Fauzi, Konstruksi Pendidikan Islam Berbasis Rahmatan Lil'alamin; Suatu Telaah Diskursif, "Journal At-Ta'lim INZAH Zainul Hasan Genggong Probolinggo Vol 4, No, no. Pendidikan Islam (2018): 57-74.

4 Ahmad Izzan, Tafsir Pendidikan Studi Ayat-Ayat Berdimensi Pendidikan, (Tangerang Selatan: Pustaka Aufa Media, 2009.), h. 20. 
Morrow menjelaskan pemerolehan bahasa pada anak terjadi melalui berbagai kegiatan yang dilakukannya, seperti mendengar bahasa dan meniru bunyi bahasa, melalui kegiatan ini akan menemukan bahwa bahasa lisan mempunyai aturan khususnya yang berkaitan dengan phonology atau bunyi, bunyi ini menghasilkan suara yang membentuk kata atau kalimat, syntax tata bahasa berkaitan dengan atauran - aturan yang berlaku pada waktu menggabungkan kata menjadi kalimat atau ungkapan, dan semantik atau arti kata berkaitan dengan makna kata, baik yang berhubungan dengan fungsi kalimat yang digunakan pada waktu berkomunikasi. ${ }^{5}$ Oleh sebab itu anak yang berada dilingkungan yang kaya dengan bahasa akan mempelajari berbagai bunyi kata dengan mudah.

Lingkungan yang kaya akan bahasa lisan membuat anak belajar berartikulasi, pengucapan, dan intonasi. Selanjutnya secara perlahan anak akan menyadari bahwa bahasa mempunyai sistem yang perlu diikuti dengan benar agar ide dan konsep yang disampaikannya dapat di terima dan di mengerti. Stimulasi yang diterima oleh anak mempengaruhi pemerolehan bahasa kedua. Bahasa pertama yang dikuasai anak juga berpengaruh terhadap pemerolehan bahasa kedua. Secara tidak sadar ketika anak mempelajari bahasa kedua, bahasa pertama yang dikuasai anak ikut mempengaruhi dalam pengucapan maupun tulisannya.

\section{Aspek Pembelajaran Bahasa}

Menyimak adalah keterampilan memahami bahasa lisan yang bersifat reseftif. Dengan demikian di sini berarti bukan sekedar mendengarkan bunyi-bunyi bahasa melainkan sekaligus memahaminya. Dalam bahasa pertama yaitu (bahasa ibu), kita memperoleh keterampilan mendengarkan melalui proses yang tidak kita sadari sehingga kitapun tidak menyadari begitu kompleksnya proses pemerolehan keterampilan mendengar tersebut. Saat bayi, manusia belum dapat mengerti kata-kata. Bayi akan lebih banyak mendengar dan menyimak bunyi-bunyi yang ada di sekelilingnya baik dari orang tua maupun lingkungannya, kemudian ia akan mulai dapat menanggapi apa yang dikatakan orang tuanya meskipun bukan dalam bahasa yang sebenarnya atau lebih seperti bergumam.

5 Martini Jamaris, 2006. PerkembangandanPengembanganAnakUsia Taman Kanakkanak. (Jakarta: Gramedia), h. 141. 
Keterampilan berbicara adalah kemampuan mengungkapkan pendapat atau pikiran dan perasaan kepada seseorang atau kelompok secara lisan, baik secara berhadapan ataupun dengan jarak jauh. Menurut Ali Mustadi tujuan pembelajaran bahasa adalah untuk berbicara Bahasa yang dipelajari termasuk kemampuan reseptif dan produkrif. ${ }^{6}$ Moris dalam Sukatmi menyatakan bahwa berbicara merupakan alat komunikasi yang alami antara anggota masyarakat untuk mengungkapkan pikiran dan sebagai sebuah bentuk tingkah laku sosial. Sedangkan, Wilkin menyatakan bahwa tujuan pengajaran bahasa Inggris dewasa ini adalah untuk berbicara. Lebih jauh lagi Wilkin menyatakan bahwa keterampilan berbicara adalah kemampuan menyusun kalimat-kalimat karena komunikasi terjadi melalui kalimatkalimat untuk menampilkan perbedaan tingkah laku yang bervariasi dari masyarakat yang berbeda. Ada banyak carabagaimana anak dapat belajar untuk berbicara dari hasil ia mendengarkan suara sejak bayi. Kemampuan berbicara pada awalnya hanya dengan huruf bilabial. Huruf bilabial adalah huruf yang terbentuk dari paduan bibir. Setelah mendengar lebih banyak kata, anak akan menyerap berbagai kosakata dan mencernanya lalu berusaha menirukannya, semakin lama anak akan belajar kata dan mengintegrasikannya dalam kalimat untuk berkomunikasi. Hal ini sesuai dengan penuturan Caroline T. Linse, When children begin speaking, they experiment and play withthe utterances that are made to form words and phrases such as bye-bye. Asthey grow, children integrate these words and structures into their real andimaginary play". Menurut Linse anak-anak bereksperimen dan bermain dengan ucapan-ucapan untuk membentuk kata-kata dan frase.

Membaca adalah suatu cara untuk mendapatkan informasi dari sesuatu yang ditulis. Membaca melibatkan pengenalan simbol yang menyusun sebuah bahasa. Membaca dan mendengar adalah dua cara paling umum untuk mendapatkan informasi. Informasi yang didapat dari membaca dapat termasuk hiburan, khususnya saat membaca cerita fiksi atau humor. Keterampilan membaca merupakan salah satu bagian dari keterampilan berfikir. Keterampilan berfikir adalah keterampilan mengolah informasi yang masuk dalam kognisi/otak manusia. Kemampuan mengolah informasi sangat ditentukan oleh tingkat pengetahuan individu.

6 Yudhi Munadi, Media Pembelajaran-Sebuah Pendekatan Baru, (Jakarta: Gaung Persada Press, 2010), h. 9. 
Salah satu aspek kebahasan yang harus dilatihkan kepada siswa adalah menulis. Menurut Tarigan keterampilan menulis merupakan suatuketerampilanberbahasayangdipergunakanuntukberkomunikasi secara tidak langsung, tidak secara tatap muka dengan orang lain ${ }^{7}$ Menulis adalah keterampilan produktif dengan menggunakan tulisan. Menulis dapat dikatakan suatu keterampilan berbahasa yang paling rumit di antara jenis-jenis keterampilan berbahasa lainnya. Ini karena menulis bukanlah sekedar menyalin kata-kata dan kalimat-kalimat, melainkan juga mengembangkan dan menuangkan pikiran-pikiran dalam suatu struktur tulisan yang teratur. Keterampilan menulis adalah kemampuan yang dimiliki seseorang dalam bidang tulis menulis sehingga tenaga potensial dalam menulis. Keterampilan menulis untuk saat sekarang telah menjadi rebutan dan setiap orang berusaha untuk dapat berperan dalam dunia menulis. Banyak orang berusaha meningkatkan keterampilan menulisnya dengan harapan dapat menjadi penulis handal.

\section{Hakikat Kosakata}

Kosakata merupakan bagian paling utama dalam keterampilan bahasa dan memberikan hal yang paling mendasar mengenai bagaimana belajar berbicara, mendengar, membaca dan menulis dengan baik. Semakin banyak kosakata yang dikuasai oleh seseorang, semakin mahir pulalah keterampilan berbicara, mendengarkan, membaca dan menulis. Setiap bahasa memiliki kosakata yang berbeda - beda dan dapat diartikan sebagai berikut : 1) kekayaan kata yang dimiliki oleh suatu bahasa, 2) semua kata yang terdapat dalam suatu bahasa, 3) kata - kata yang dipakai disuatu bidang ilmu pengetahuan, 4) kamus sederhana dalam betuk ringkas, daftar kata - kata tertentu dengan penjelasannya ${ }^{8}$. Diperkuat oleh pendapat yang menyatakan bahwa, kosakata merupakan kumpulan kata - kata yang terdapat dalam suatu bahasa dan memiliki arti ketika digunakan oleh seseorang serta memberikan makna bila seseorang menggunakan bahasa tersebut ${ }^{9}$

7 Novianto, Anwar dan Ali Mustadi, Analisis Buku Teks Muatan Tematik Integratif, Scientific Approach, dan Authentic Assessment Sekolah Dasar, (Jurnal Kependidikan, Volume 45, Nomor 1, Mei 2015), h. 2

8 Yayat Sudrajat, Makna dalam Wacana. (Bandung: CV. Yrama Widya, 2009), h. 65 .

9 Suyanto, Slamet, Konsep Dasar Pendidikan Anak Usia Dini. (Jakarta: Departemen Pendidikan Nasional, 2005), h. 43 
Dari pendapat diatas dapat disimpulkan bahwa yang di maksud dengan kosakata dalam penelitian ini adalah pembendaharaan atau kumpulan kata yang dimiliki suatu bahasa yang memberikan makna atau arti bila seseorang menggunakan bahasa.

\section{Hakikat Media Video Compact Disk}

VCD (Video Compact Disk) adalah bahan ajar yang merupakan kombinasi dari dua atau lebih media (audio, teks, grafik, gambar animasi, dan video) dimana pengoperasiannya perlu alat untuk menayangkan seperti TV, CD, komputer, dan proyektor (Majid, 2006). Media ini dapat menyajikan informasi, memaparkan proses, memperjelas konsep yang rumit, mengajarkan keterampilan, menyingkat atau memperpanjang waktu dan mempengaruhi sikap. ${ }^{10}$ Video/VCD pembelajaran adalah suatu media yang dirancang secara sistematis dengan berpedoman kepada kurikulum yang berlaku dan dalam pengembangannya mengaplikasikanprinsip pembelajaran sehingga program tersebut memungkinkan peserta didik mencerna materi pelajaran secara lebih mudah dan menarik.

VCD pembelajaran merupakan media atau bahan ajar audiovisual, media ini biasanya disebut sebagai alat bantu pandang dengar (audio visual aids/audio visual media). Umumnya program video telah dibuat dalam rancangan lengkap, sehingga setiap akhir dari penayangan video siswa dapat menguasai satu atau lebih kompetensi dasar. Baik tidaknya program video tentu saja tergantung pada desain awalnya, mulai analisis kurikulum, pengetahuan media, skema yang menunjukan skenario dari sebuah program video, film, strip, pengambilan gambar dan proses editingnya. Penggunaan VCD pembelajaran dilakukan ketika pembelajaran berlangsung, dapat dilakukan di ruang kelas maupun di ruang peraga tergantung fasilitas yang dimiliki oleh masing-masing sekolah. Waktu yang diperlukan dalam menggunakan media VCD pembelajaran tergantung pada panjang video dan cakupan materinya, media ini digunakan dalam proses pembelajaran yang dapat dilakukan oleh semua guru baik guru TK, SD, SLTP, SMU serta dosen di Perguruan Tinggi. VCD berisi pesan atau informasi yang digunakan dalam kegiatan belajar mengajar dengan maksud sebagai penyampaikan pesan atau informasi

${ }^{10}$ Sufren, dan Natanael, Yonathan, Mahir Menggunakan SPSS Secara Otodidak. (Jakarta: Kompas Gramedia, 2003), h. 68. 
pembelajaran dari sumber (guru atau sumber lain) kepada penerima pesan (peserta didik). ${ }^{11}$

\section{Medode Penelitian}

Penelitian ini adalah penelitian tindakan dengan model Kemmis dan Taggart yang terdiri dari 4 tahap yaitu (rencana, tindakan, observasi dan refleksi). Penelitian ini terdiri dari 2 siklus, dengan masing-masing siklus sebanyak empat kali pertemuan. Teknik pengumpulan data yaitu menggunakan observasi, catatan lapangan, dan dokumentasi. Analisis data menggunakan kuantitatif dan kualitatif. Analisis data kuantitatif dilakukan dengan deskripsi statistik untuk membandingkan pra siklus sampai pada siklus II.

\section{Hasil Penelitian dan Pembahasan}

Berikut ini merupakan hasil pretes penguasaan kosakata bahasa Inggris siswa kelas II SD N Rorotan 03 Pagi Kelurahan Rorotan Kecamatan Cilincing Jakrta Utara:

Tabel 1. 1

Hasil Pretes Penguasaan Kosakata Bahasa Inggris

\begin{tabular}{|c|c|l|c|l|}
\hline NO & INDUK & \multicolumn{1}{|c|}{ NAMA SISWA } & Nilai & \multicolumn{1}{|c|}{ Keterangan } \\
\hline 1 & 5332 & AR & 70 & Tuntas \\
\hline 2 & 5333 & AI & 46 & Tidak Tuntas \\
\hline 3 & 5334 & AR & 45 & Tidak Tuntas \\
\hline 4 & 5335 & AP & 70 & Tuntas \\
\hline 5 & 5336 & AI & 70 & Tidak Tuntas \\
\hline 6 & 5337 & BH & 40 & Tidak Tuntas \\
\hline 7 & 5338 & BR & 70 & Tuntas \\
\hline 8 & 5339 & DY & 35 & Tidak Tuntas \\
\hline 9 & 5340 & DI & 70 & Tuntas \\
\hline 10 & 5341 & FM & 50 & Tidak Tuntas \\
\hline 11 & 5342 & GA & 45 & Tidak Tuntas \\
\hline 12 & 5343 & HT & 72 & Tuntas \\
\hline 13 & 5344 & IT & 55 & Tidak Tuntas \\
\hline
\end{tabular}

${ }^{11}$ Yudhi Munadi, Media Pembelajaran-Sebuah Pendekatan Baru, (Jakarta: Gaung Persada Press, 2010), h. 137. 


\begin{tabular}{|c|c|l|c|l|}
\hline NO & INDUK & \multicolumn{1}{|c|}{ NAMA SISWA } & Nilai & \multicolumn{1}{|c|}{ Keterangan } \\
\hline 14 & 5345 & KA & 70 & Tidak Tuntas \\
\hline 15 & 5346 & KJ & 50 & Tidak Tuntas \\
\hline 16 & 5347 & KR & 55 & Tidak Tuntas \\
\hline 17 & 5348 & LA & 70 & Tuntas \\
\hline 18 & 5349 & MK & 45 & Tidak Tuntas \\
\hline 19 & 5350 & MA & 48 & Tidak Tuntas \\
\hline 20 & 5351 & MA & 50 & Tidak Tuntas \\
\hline 21 & 5352 & MF & 70 & Tuntas \\
\hline 22 & 5353 & NS & 70 & Tuntas \\
\hline 23 & 5354 & ND & 55 & Tidak Tuntas \\
\hline 24 & 5355 & NA & 50 & Tidak Tuntas \\
\hline 25 & 5356 & RP & 75 & Tuntas \\
\hline 26 & 5357 & RA & 45 & Tidak Tuntas \\
\hline 27 & 5358 & RP & 73 & Tuntas \\
\hline 28 & 5359 & RA & 40 & Tidak Tuntas \\
\hline 29 & 5360 & RS & 70 & Tuntas \\
\hline 30 & 5361 & SN & 55 & Tidak Tuntas \\
\hline 31 & 5362 & SF & 74 & Tuntas \\
\hline 32 & 5363 & WO & 58.53 & Tidak Tuntas \\
\hline & & Rata-Rata & & \\
\hline
\end{tabular}

Dari hasil pretes yang dilakukan sebelum masuk pada siklus I rata-rata nilai yang didapatkan adalah 58. $53 \%$. Dari pretes yang dilakukan pada siklus I ada 20 siswa yang belum tuntas. Setelah peneliti memberikan tindakan pada siklus pertama, siswa dites kembali melalui tes akhir siklus I dengan soal yang sama. Berikut hasit tes siklus pertama penguasaan kosakata bahasa Inggris siswa kelas II SD N Rorotan 03 Pagi Kelurahan Rorotan Kecamatan Cilincing Jakrta Utara 
Tabel 1. 2

Hasil Tes Siklus Pertama Penguasaan Kosakata Bahasa Inggris

\begin{tabular}{|c|c|c|c|c|}
\hline NO & INDUK & NAMA SISWA & Nilai & Keterangan \\
\hline 1 & 5332 & AR & 75 & Tuntas \\
\hline 2 & 5333 & $\mathrm{AI}$ & 65 & Tidak Tuntas \\
\hline 3 & 5334 & AR & 72 & Tuntas \\
\hline 4 & 5335 & $\mathrm{AP}$ & 80 & Tuntas \\
\hline 5 & 5336 & $\mathrm{AI}$ & 80 & Tuntas \\
\hline 6 & 5337 & $\mathrm{BH}$ & 70 & Tuntas \\
\hline 7 & 5338 & $\mathrm{BR}$ & 70 & Tuntas \\
\hline 8 & 5339 & DY & 75 & Tuntas \\
\hline 9 & 5340 & DI & 70 & Tuntas \\
\hline 10 & 5341 & FM & 70 & Tuntas \\
\hline 11 & 5342 & GA & 80 & Tuntas \\
\hline 12 & 5343 & $\mathrm{HT}$ & 74 & Tuntas \\
\hline 13 & 5344 & IT & 65 & Tidak Tuntas \\
\hline 14 & 5345 & KA & 75 & Tuntas \\
\hline 15 & 5346 & KJ & 60 & Tidak Tuntas \\
\hline 16 & 5347 & $\mathrm{KR}$ & 60 & Tidak Tuntas \\
\hline 17 & 5348 & LA & 65 & Tidak Tuntas \\
\hline 18 & 5349 & MK & 70 & Tuntas \\
\hline 19 & 5350 & MA & 70 & Tuntas \\
\hline 20 & 5351 & MA & 75 & Tuntas \\
\hline 21 & 5352 & MF & 75 & Tuntas \\
\hline 22 & 5353 & NS & 76 & Tuntas \\
\hline 23 & 5354 & ND & 60 & Tidak Tuntas \\
\hline 24 & 5355 & NA & 65 & Tidak Tuntas \\
\hline 25 & 5356 & $\mathrm{RP}$ & 82 & Tuntas \\
\hline 26 & 5357 & RA & 70 & Tuntas \\
\hline 27 & 5358 & $\mathrm{RP}$ & 78 & Tuntas \\
\hline 28 & 5359 & RA & 60 & Tidak Tuntas \\
\hline 29 & 5360 & RS & 80 & Tuntas \\
\hline 30 & 5361 & $\mathrm{SN}$ & 60 & Tidak Tuntas \\
\hline 31 & 5362 & SF & 75 & Tuntas \\
\hline
\end{tabular}




\begin{tabular}{|c|c|l|c|l|}
\hline NO & INDUK & \multicolumn{1}{|c|}{ NAMA SISWA } & Nilai & Keterangan \\
\hline 32 & 5363 & WO & 80 & Tuntas \\
\hline \multicolumn{2}{|c|}{ Rata-Rata } & 71.31 & Tuntas \\
\hline
\end{tabular}

Setelah diketahui nilai akhir siklus pertama dan rata-rata nilai masih sudah memenuhi persyaratan nilai standar yaitu hasilnya adalah 71, $31 \%$. Ada 9 anak yang belum tuntas agar terdapat penguasaan maka dilakukan penelitian pada siklus kedua, kosakata bahasa inggris siswa kelas II SD N Rorotan 03 Pagi Kelurahan Rorotan Kecamatan Cilincing Jakrta Utara

Tabel 1.3

Hasil Tes Siklus Kedua Penguasaan Kosakata Bahasa Inggris

\begin{tabular}{|c|c|l|c|l|}
\hline NO & INDUK & \multicolumn{1}{|c|}{ NAMA SISWA } & Nilai & \multicolumn{1}{|c|}{ Keterangan } \\
\hline 1 & 5332 & AR & 80 & Tuntas \\
\hline 2 & 5333 & AI & 75 & Tuntas \\
\hline 3 & 5334 & AR & 85 & Tuntas \\
\hline 4 & 5335 & AP & 95 & Tuntas \\
\hline 5 & 5336 & AI & 94 & Tuntas \\
\hline 6 & 5337 & BH & 88 & Tuntas \\
\hline 7 & 5338 & BR & 85 & Tuntas \\
\hline 8 & 5339 & DY & 88 & Tuntas \\
\hline 9 & 5340 & DI & 85 & Tuntas \\
\hline 10 & 5341 & FM & 85 & Tuntas \\
\hline 11 & 5342 & GA & 90 & Tuntas \\
\hline 12 & 5343 & HT & 90 & Tuntas \\
\hline 13 & 5344 & IT & 90 & Tuntas \\
\hline 14 & 5345 & KA & 80 & Tuntas \\
\hline 15 & 5346 & KJ & 75 & Tuntas \\
\hline 16 & 5347 & KR & 80 & Tuntas \\
\hline 17 & 5348 & LA & 85 & Tuntas \\
\hline 18 & 5349 & MK & 85 & Tuntas \\
\hline 19 & 5350 & MA & 80 & Tuntas \\
\hline 20 & 5351 & MA & & \\
\hline & & & Tuntas \\
\hline
\end{tabular}




\begin{tabular}{|c|c|l|c|l|}
\hline NO & INDUK & \multicolumn{1}{|c|}{ NAMA SISWA } & Nilai & \multicolumn{1}{|c|}{ Keterangan } \\
\hline 21 & 5352 & MF & 80 & Tuntas \\
\hline 22 & 5353 & NS & 85 & Tuntas \\
\hline 23 & 5354 & ND & 75 & Tuntas \\
\hline 24 & 5355 & NA & 80 & Tuntas \\
\hline 25 & 5356 & RP & 95 & Tuntas \\
\hline 26 & 5357 & RA & 85 & Tuntas \\
\hline 27 & 5358 & RP & 75 & Tuntas \\
\hline 28 & 5359 & RA & 95 & Tuntas \\
\hline 29 & 5360 & RS & 70 & Tuntas \\
\hline 30 & 5361 & SN & 85 & Tuntas \\
\hline 31 & 5362 & SF & 84.06 & Tuntas \\
\hline 32 & 5363 & WO & & \\
\hline \multicolumn{2}{|c|}{ Rata-Rata } &
\end{tabular}

Data analisis kuantitatif juga akan ditampiikan dalam bentuk grafik untuk mempermudah pemahaman tentang perkembangan nilai prestasi belajar siswa. Draf tersebut adalah sebagai berikut :

\section{Grafik 1.4}

Nilai Pretes Penguasaan Kosakata Bahasa Inggris Siswa Kelas II SD N Rorotan 03 Pagi Kelurahan Rorotan Cilincing Jakrta Utara

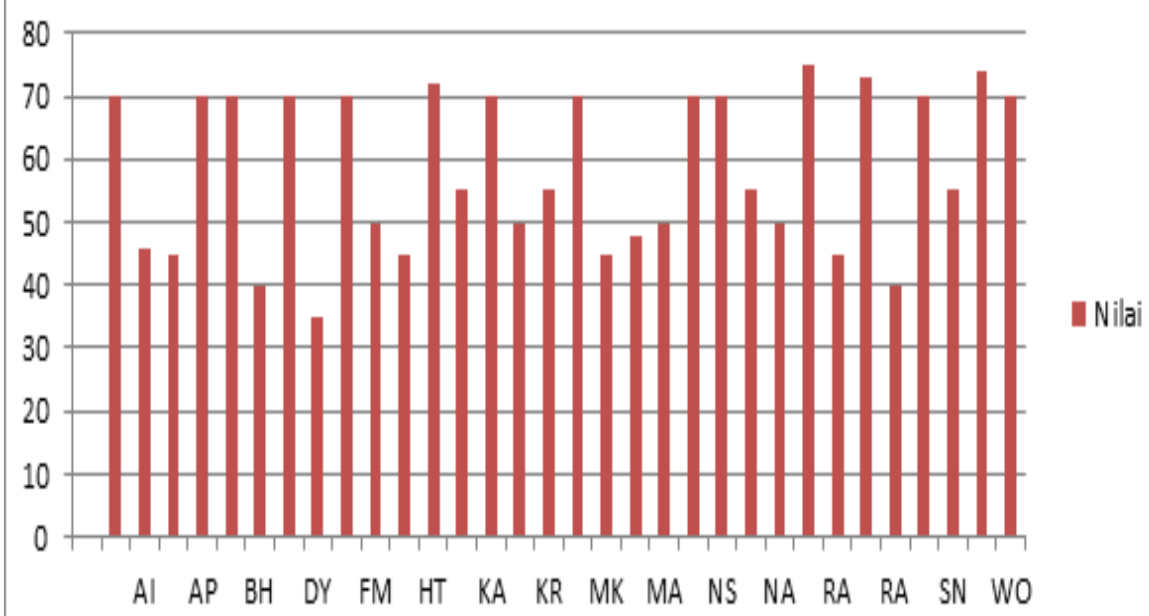


Pada pretes siswa hanya memperoleh nilai rata-rata 58, $53 \%$ (dalam skala 100). Nilai rata-rata yang diperoleh pada pretes belum memenuhi syarat KKM hanya sebesar 58, 53 \%, sedangkan syarat nilai KKM sebesar 70. Setelah peneliti memberikan tindakan pada sikius pertama, siswa dites kembali meialui tes akhir siklus I dengan soal yang sama. Berikut hasil tes siklus II penguasaan kosakata bahasa Inggris Siswa Kelas II SD N Rorotan 03 Pagi Kelurahan Rorotan Kecamatan Cilincing Jakrta Utara.

\section{Gafik 1. 5}

Nilai Tes Siklus I Penguasaan Kosakata Bahasa inggris Siswa Kelas II SD N Rorotan 03 Pagi Kelurahan Rorotan Cilincing Jakrta Utara

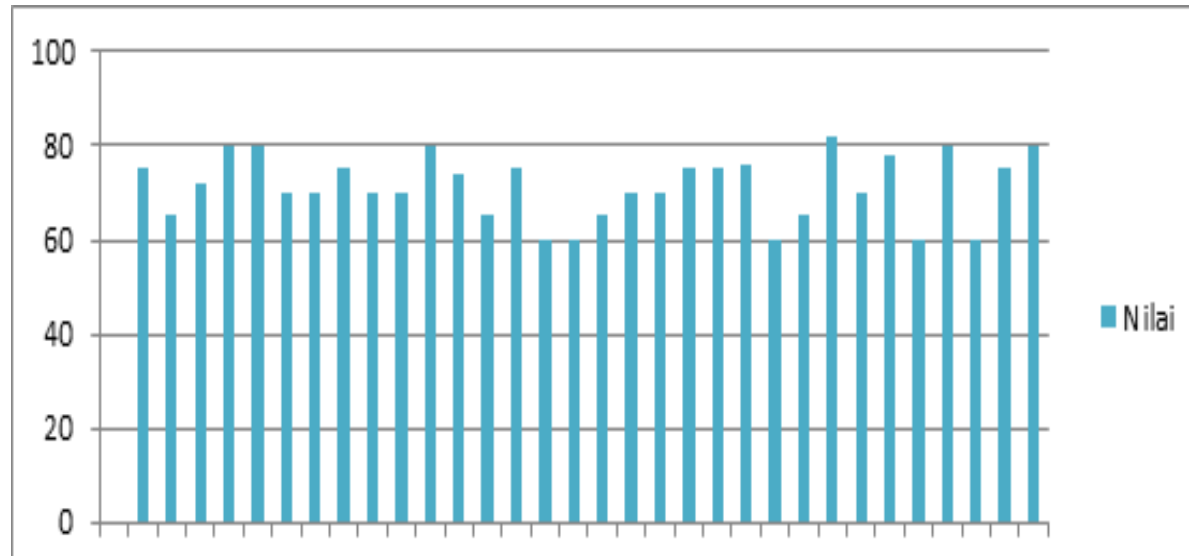

AI AP BH DY FM HT KA KR MK MA NS NA RA RA SN WO

Pada akhir siklus I siswa hanya memperoleh nilai rata-rata 71, 31 $\%$ (dalam skala100) Niliai rata-rata yang diperoleh pada siklus I sudah memenuhi syarat KKM yaitu sebesar 71, 31 \% sedangkan nilai KKM sebesar 70. Ada 9 anak yang masih belum memenuhi persyaratan nilai standar, maka peneliti melakukan tes kembali pada siklus II (post test). Berikut hasil tes siklus II penguasaan kosakata bahasa lnggris Siswa Kelas II SD N Rorotan 03 Pagi Kelurahan Rorotan Kecamatan Cilincing Jakarta Utara. 
Grafik 1.6

Nilai Tes Siklus II Penguasaan Kosakata Bahasa Inggris Siswa Kelas II SD N Rorotan 03 Pagi Kelurahan Rorotan Cilincing Jakarta Utara

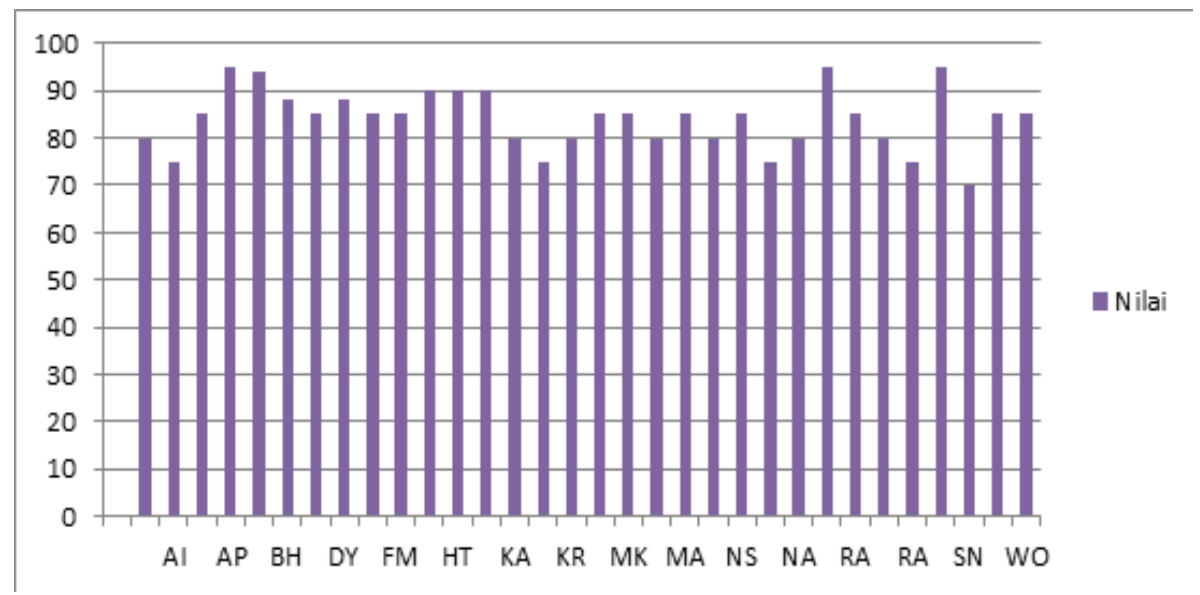

Pada akhir siklus II terdapat peningkatan yang cukup signifikan. Nilai rata-rata siswa mencapai 84, 06 (dalam skala 100), yang sebelumnya pada akhir siklus I hanya memperoleh nilai rata-rata. Maka pada siklus II sudah memenuhi standar KKM.

Dengan demikian dapat dikatakan bahwa terdapat peningkatan hasil tes awal (pretes) dengan tes akhir (post test) penguasaan kosakata bahasa !nggris siswa kelas II SD N Rorotan 03 Pagi Kelurahan Rorotan Kecamatan Cilincing Jakrta Utara. Data analisis kuantitatif juga akan ditampilkan dalam bentuk grafik gabungan untuk mempermudah pemahaman tentang perkembangan nilai prestasi belajar siswa. Grafik tersebut adalah sebagai berikut : 


\section{Grafik 1.7}

Perkembangan Nilai Tes Penguasaan Kosakata Bahasa Inggris Siswa

SD N Rorotan 03 Pagi Kelurahan Rorotan Cilincing Jakarta Utara

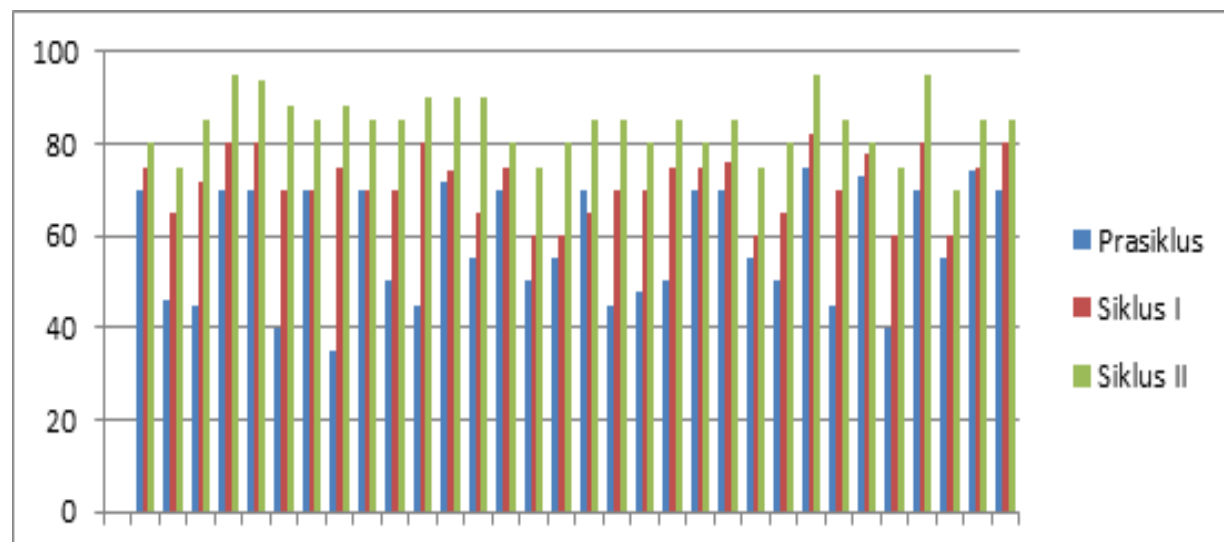

AI AP BH DY FM HT KA KR MK MA NS NA RA RA SN WO

Data analisis kuantitatif juga akan menampilkan kan bentuk grafik rata-rata pretes, siklus I dan siklus II untuk mempermudah pemahaman tentang perkembangan nilai prestasi belajar bahasa Inggris siswa. Nilai rata-rata pretes adalah 58, $53 \%$, nilai rata-rata siklus I adalah 71, $31 \%$ dan nilai rata-rata siklus II adalah 84, $06 \%$ Grafiik tersebut adalah sebagai berikut:

\section{Grafik 1.8}

Nilai Rata-rata Tes Penguasaan Kosakata Bahasa Inggris Siswa Kelas II SD N Rorotan 03 Pagi Kelurahan Rorotan Cilincing Jakrta Utara

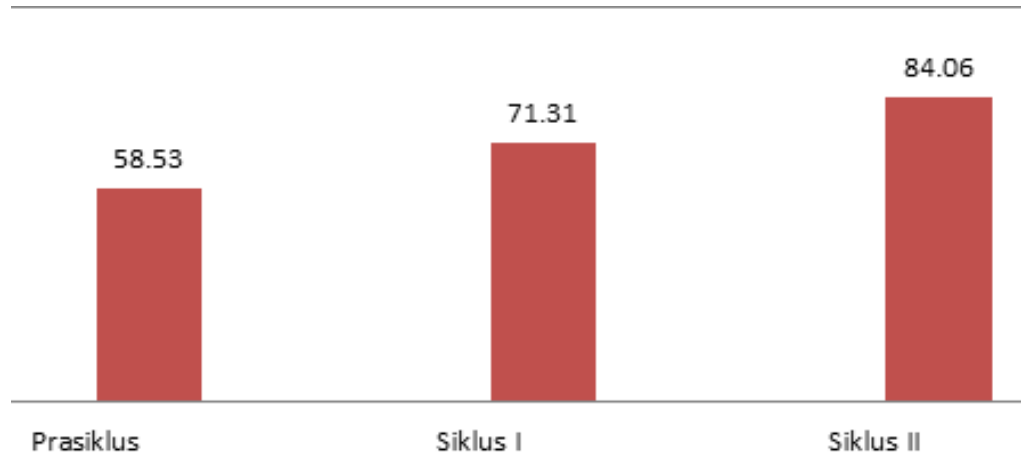


Berdasarkan hasil pelaksanaan penelitian tindakan untuk meningkatarn penguasaan kosakata bahasa lnggris kelas II SD $\mathrm{N}$ Rorotan 03 Pagi Kelurahan Rorotan Kecamatan Cilincing Jakarta Utara, maka ditemukan hasil penelitian selama dua siklus. Temuan penelitian ini berupa sumber data kualitatif dan sumber data kuantitatif penelitian ini berupa sumber data kualitatif dan sumber data kuantitif. Setelah peneliti menganalisa data kualitatif dan kuantitatit dapat diketahui adanya peningkatan penguasaan kosakata bahasa Inggris Siswa Kelas II SD N Rorotan 03 Pagi Kelurahan Rorotan Kecamatan Cilincing Jakrta Utara. Peningkatan ini dapat dilihat dari kemajuan, kreatifiitas, dan produktifitas siswa dalam mengikut, KBM. hanya itu, peningkatan tersebut terlihat pula dari perkembangan kemajuan nilai tes awal sampai tes akhir yang terus meningkat. Hal ini disebabkan oleh penerapan adanya pembelajaran dengan media Compact Disk Digital (VCD) sehingga menciptakan pembelajaran lebih menyenangkan dan tidak kaku serta modern. Sehingga siswa dapat bebas berkarya dan berkreativitas serta melakukan inovasi untuk menggali potensi yang sudah dimiliki pada saat KBM berlangsung.

Sifat dasar anak-anak pada tingkat sekolah dasar suka dengan hal-hal yang baru dan menarik sehingga dengan adanya pembelajaran yang modern mampu memberikan semangat siswa dalam belajar, aktif disetiap proses KBM dan mampu berkompetisi yang ditunjukkan dengan kemajuan nilai pretes, tes pada siklus I dan nilai tes pada siklus II dalam menguasai kosakata bahasa Inggris. Hal tersebut sesuai dengan penelitian yang dilakukan Abdurrachman Faridi, yang berjudul English Learning Innovation Based on ICT in Order to Increase Educational Quality, bahawa ICT merupakan wujud kemajuan ilmu pengetahuan dan teknologi yang harus terus dioptimalkan, terutama dalam pelaksanakan pembelajaran bahasa Inggris. Selain itu ICT mampu memberikan peluang yang seluas-luasnya kepada siswa untuk mengasah dan memacu kompetensinya dalam skala internasional. Di sisi lain, sikap mental dan kemadirian dalam mengakses segala infromasi pembelajaran yang dibutuhkan secara mandiri memberikan pengaruh dalam penanaman nilai-nilai kepribadian siswa.

\section{Kesimpulan}

Peningkatan kemampuan kosa kata bahasa Inggris pada siswa kelas II SDN Rorotan 03 Pagi yang dicapai siswa pada setiap siklus 
menunjukan adanya peningkatan yang baik. hasil belajar kosakata pada pra siklus dari 32 anak dengan rata-rata 58, 53 \% sehingga hasil tersebut belum mencapai KKM, kemudian dilanjutkan pada siklus I mengalami kenaikan rata-rata kemampuan kosa kata menjadi 71, 31 \% selanjutnya pada siklus II kemampuan rata-rata kosa kata bahasa Inggrisnya sebanyak $84,06 \%$. Bahwa metode media compact disk digital dapat meningkatkan kemampuan kosa kata bahasa Inggris terbukti bahwa setiap siklus mengalami kenaikan pada setiap siklusnya. 


\section{DAFTAR PUSTAKA}

Ahmad Izzan, H, Drs, M. Ag dkk. 2009. Tafsir Pendidikan Studi AyatAyat Berdimensi Pendidikan. Tangerang Selatan: Pustaka Aufa Media

Fauzi, Ahmad. "Konstruksi Pendidikan Islam Berbasis Rahmatan Lil'alamin; Suatu Telaah Diskursif. " Journal At-Ta'lim INZAH Zainul Hasan Genggong Probolinggo Vol 4, No, no. Pendidikan Islam (2018): $57-74$.

Jamaris, Martini. 2006. PerkembangandanPengembanganAnakUsia Taman Kanak-kanak. Jakarta: Gramedia

Novianto, Anwar dan Ali Mustadi. 2015. Analisis Buku Teks Muatan Tematik Integratif, Scientific Approach, dan Authentic Assessment Sekolah Dasar. Jurnal Kependidikan, Volume 45, Nomor 1, Mei 2015, Halaman 1-15

Sudrajat, Yayat. 2009. Makna dalam Wacana. Bandung: CV. Yrama Widya

Sukatmi. 2009. Upaya Meningkatkan Keterampilan Berbicara dengan Media Gambar. Tesis Universitas Sebelas Maret. Tersedia di http:// core. ac. uk/download/pdf/16507061. pdf. Diunduh 26 Oktober 2015.

Sufren, dan Natanael, Yonathan. 2013. Mahir Menggunakan SPSS Secara Otodidak, Jakarta: Kompas Gramedia

Suharsimi, Arikunto. 2006. Prosedur Penelitian Pendidikan (Suatu Pendekatan Praktik). Jakarta: Bumi Aksara.

Fauzi, Ahmad. "Organizational Culture of Islamic Public Education Management a Discurtive. " In International Conference On Islamic Education (ICIED) Innovations, Approaches, Challenges, And The Future, 130-36. Malang: Fakultas Ilmu Tarbiyah dan Keguruan UIN Maulana Malik Ibrahim Malang, 2017.

Sugiyono. 2003. Metode Penelitian Bisnis. Bandung:Pusat Bahasa Depdiknas.

Suyanto, Slamet. 2005. Konsep Dasar Pendidikan Anak Usia Dini. Jakarta: Departemen Pendidikan Nasional.

Munadi, Yudhi. (2010). Media Pembelajaran -SebuahPendekatanBaru. Jakarta: GaungPersadaPress. 